\title{
A double-blind controlled trial of high dose methylprednisolone in patients with multiple sclerosis: 1. clinical effects
}

\author{
N M MilligAN,* R NEWCOMBE, $\dagger$ D A S COMPSTON* \\ From the Departments of Neurology, ${ }^{*}$ and Medical Statistics, $\dagger$ University of Wales College of Medicine, \\ Cardiff, UK
}

\begin{abstract}
SUMMARY - A randomised double-blind, placebo-controlled trial of high-dose, pulsed intravenous methylprédnisolone was carried out in 50 individuals with multiple sclerosis; 22 patients were in acute relapse and 28 had chronic progressive disease. After a baseline assessment using the Kurtzke functional and expanded disability status scales each patient was randomly allocated to intravenous treatment with methylprednisolone $(500 \mathrm{mg})$ or a saline placebo administered as a single daily dose for 5 days. Clinical assessments were repeated at 1 and 4 weeks after starting treatment. The results from all 50 patients showed a highly significant effect in favour of methylprednisolone treatment ( $p$ $<0.001)$. In patients with relapse, there was a significant decrease in clinical disability scores at 1 and 4 weeks in the methylprednisolone treated group compared with controls $(p<0.05$ for each comparison). In the chronic progressive group, disability scores at 4 weeks only were significantly lower after treatment with methylprednisolone $(p<0.01)$, mainly attributable to improvement in pyramidal function.
\end{abstract}

Corticosteroids increase the rate of recovery from relapse in multiple sclerosis ${ }^{12}$ but do not affect the long term course of the disease. ${ }^{3-5}$ However, recovery from relapse after conventional treatment with intramuscular ACTH or oral corticosteroids often develops slowly and prolonged courses of treatment increase the likelihood of adverse effects. Recently, high-dose pulsed intravenous methylprednisolone has been used with success in the management of immunologically mediated diseases ${ }^{6-9}$ and similar treatment regimens, given openly, have been reported to be beneficial in acute exacerbations of multiple sclerosis. ${ }^{10-13}$ Dowling, Bosch and Cook ${ }^{10}$ observed rapid clinical improvement with minimal side effects in five out of seven patients with acute demyelinating lesions who were given high-dose intravenous methylprednisolone and in the short term, Barnes et al ${ }^{14}$ found this treatment more effective than intramuscular ACTH. Despite promising results from uncontrolled pilot studies few controlled trials of this

Address for reprint requests: Dr DAS Compston, University of Wales College of Medicine, Heath Park, Cardiff CF44XN, UK.

Received 13 May 1986.

Accepted 3 July 1986 treatment in multiple sclerosis have been published and the mechanism of action of methylprednisolone is uncertain. Furthermore, most studies have reported the use of intravenous methylprednisolone in patients with acute relapsing multiple sclerosis and the possible role of this treatment in other forms of the disease has not been adequately investigated. This report presents the results of a controlled trial of intravenous methylprednisolone in patients with acute exacerbations of multiple sclerosis or chronic progressive disease. Laboratory investigations were carried out in an attempt to determine the possible mode of action of the drug and are reported separately. ${ }^{15}$

\section{Patients and methods}

Fifty patients, mean age 36.9 (range 18-67) years gave informed consent to take part in this study. Clinical details are given in table 1. Patients were classified using the criteria of McDonald and Halliday ${ }^{16}$ with the modification that a minimum disease duration of one year was not essential for inclusion. Patients were either studied in acute relapse $(\mathbf{n}=$ 22 ) or they had chronic progressive disease $(n=28)$. Each group was separately randomised. Relapse was defined as the occurrence of one or more new, or a worsening of existing symptoms of less than 8 weeks but more than 24 hours 
Table 1 Clinical details in 50 patients with multiple sclerosis treated with methylprednisolone or placebo

\begin{tabular}{|c|c|c|c|c|c|c|c|c|c|c|c|}
\hline & \multirow[b]{2}{*}{$\begin{array}{l}\text { Age } \\
(y r)\end{array}$} & \multirow[b]{2}{*}{$\begin{array}{l}\text { Sex } \\
F / M\end{array}$} & \multirow[b]{2}{*}{$\begin{array}{l}\text { Age } \\
\text { at onset } \\
(y r)\end{array}$} & \multirow[b]{2}{*}{$\begin{array}{l}\text { Clinically } \\
\text { definite }\end{array}$} & \multirow[b]{2}{*}{$\begin{array}{l}\text { Early } \\
\text { probable } \\
\text { multiple } \\
\text { selerosis }\end{array}$} & \multicolumn{2}{|c|}{ Progressive } & \multirow[b]{2}{*}{$\begin{array}{l}\text { Suspected } \\
\text { multiple } \\
\text { sclerosis }\end{array}$} & \multirow[b]{2}{*}{$\begin{array}{l}\text { Duration } \\
\text { of disease } \\
(y r)\end{array}$} & \multirow[b]{2}{*}{$\begin{array}{l}\text { Duration } \\
\text { of relapse } \\
\text { (weeks) }\end{array}$} & \multirow[b]{2}{*}{$\begin{array}{l}\text { Duration } \\
\text { progressiơ } \\
\text { (yr) }\end{array}$} \\
\hline & & & & & & $\begin{array}{l}\text { Probable } \\
\text { multiple } \\
\text { sclerosis }\end{array}$ & $\begin{array}{l}\text { Possible } \\
\text { multiple } \\
\text { sclerosis }\end{array}$ & & & & \\
\hline $\begin{array}{l}\text { Acute } \\
\text { relapse } \\
n=22\end{array}$ & $34 \cdot 1 \pm 9 \cdot 9$ & $18 / 4$ & $28 \cdot 6 \pm 8 \cdot 3$ & 16 & 1 & 3 & 1 & 1 & $5.4 \pm 6.6$ & $4 \pm 1 \cdot 7$ & - \\
\hline $\begin{array}{c}\text { Progressive } \\
\text { multiple } \\
\text { sclerosis } \\
n=28\end{array}$ & $39 \cdot 8 \pm 10 \cdot 5$ & $16 / 12$ & $33 \pm 10.4$ & 19 & 0 & 3 & 5 & 1 & $7 \cdot 1 \pm 5 \cdot 5$ & - & $3.7 \pm 3 \cdot 2 \underset{\overline{\bar{\sigma}}}{\stackrel{3}{\overline{0}}}$ \\
\hline
\end{tabular}

duration, which had not improved spontaneously at the time of entry into the trial. The duration of the progressive phase, identified retrospectively from case records, was more than one year in most cases (mean $3 \cdot 7$; range $0.5-11$ years). Patients with isolated optic neuritis were not studied and those with medical conditions (diabetes, severe heart disease, hypertension, pregnancy) that would either interfere with neurological assessment or represent a contra-indication to treatment with high dose corticosteroids were excluded.

All patients were assessed at entry under double-blind conditions using the Kurtzke functional and expanded disability status scales. They were then randomly allocated to treatment with methylprednisolone $500 \mathrm{mgs}$. (SoluMedrone, Upjohn) dissolved in $7.8 \mathrm{ml}$ of benzyl alcohol $(0.9 \% \mathrm{w} / \mathrm{v})$ or an equivalent volume of saline reconstituted in $100 \mathrm{ml}$ of normal saline and given as a single daily dose for 5 days by intravenous infusion over 1 hour. Following a repeat clinical examination at one week patients were discharged from hospital and admitted for re-assessment at 4 weeks or they remained in hospital until discharge was appropriate. Physiotherapy was given when necessary and all pre-existing medications was continued throughout the trial. All control patients in relapse showing no improvement, or further progression of disability at the end of the study, were subsequently offered treatment with intravenous methylprednisolone or oral prednisolone.

Visual evoked potentials were recorded and samples of peripheral blood and cerebrospinal fluid taken before randomisation and at 4 weeks for laboratory measurements, the results of which are reported elsewhere. ${ }^{15}$

\section{Statistical analysis}

Analyses of covariance, using disability score at 1 or 4 weeks as the outcome and corresponding baseline assessments as covariate, have been used to compare active and placebo treatment. The Kurtzke disability scale is not linear and numerically equivalent changes do not carry the same clinical significance at different points on the scale, so that the analyses were repeated using the non-parametric MannWhitney tests. Differences in age, age at onset, duration of disease or relapse, or the progressive phase, between the two treatment groups were assessed using Student's $t$ test.

\section{Results}

In patienis with acute relapse there were no statistical differences in age, age at onset, duration of disease or relapse and clinical disability at entry into the trial. In patients with progressive multiple sclerosis the mean age in the methylprednisolone treated group was 34.4 $( \pm 7 \cdot 7)$ years, compared with $44.9( \pm 13 \cdot 3)$ years in controls and the mean age at onset in the actively treated group was $27 \cdot 1( \pm 7 \cdot 9)$ years compared with $39( \pm 13)$ years in controls. These differences were statistically significant $(\mathrm{p}<0.05$ and $\mathrm{p}<0.01$ respectively). Clinical disability scores were significantly higher at entry in methylprednisolone

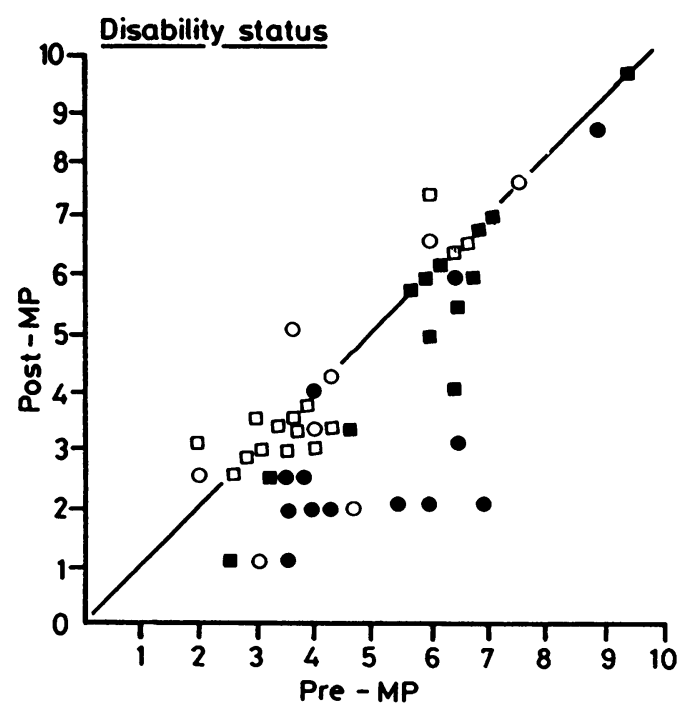

Fig Clinical disability scores before (horizontal axis) and 4 weeks after (vertical axis) treatment in 50 patients with multiple sclerosis. Methylprednisolone, acute relapse (O); methylprednisolone, chronic progression ( $\square$ ); placebo, acute relapse (O); placebo, chronic progression ( $\square$ ). Cases in whom disability scores did not change appear on, or adjacent to, the diagonal line. A decreased disability score after treatment is indicated by a point below, and an increased disability score by a point above this line. Analysis of covariance revealed a significant effect in favour of methylprednisolone treatment $(t=-3.85 ; p<0.001)$. 
Table 2 Results of treatment in patients with acute relapse

\begin{tabular}{|c|c|c|c|c|c|}
\hline \multirow[b]{2}{*}{ Case } & \multirow[b]{2}{*}{ Age/sex } & \multirow{2}{*}{$\begin{array}{l}\text { Age at onset } \\
(y r)\end{array}$} & \multicolumn{3}{|c|}{ Disability Status Scale } \\
\hline & & & Entry & l week & 4 weeks \\
\hline \multicolumn{6}{|c|}{ Methylprednisolone } \\
\hline 1 & $31 / \mathrm{F}$ & 22 & 7 & $2 \cdot 5$ & 2 \\
\hline 2 & $31 / \mathrm{F}$ & 31 & $3 \cdot 5$ & $3 \cdot 5$ & $2 \cdot 5$ \\
\hline 3 & $39 / \mathrm{F}$ & 34 & $6 \cdot 5$ & 4 & 3 \\
\hline 4 & $33 / F$ & 26 & 6 & 3 & 2 \\
\hline 5 & $42 / \mathrm{F}$ & 42 & $6 \cdot 5$ & 6 & 6 \\
\hline 6 & $37 / F$ & 27 & $3 \cdot 5$ & 2 & 1 \\
\hline 7 & $38 / \mathrm{M}$ & 38 & $3 \cdot 5$ & 3 & 2 \\
\hline 8 & $23 / \mathrm{F}$ & 23 & 9 & $8 \cdot 5$ & $8 \cdot 5$ \\
\hline 9 & $27 / \mathrm{M}$ & 27 & $5 \cdot 5$ & $2 \cdot 5$ & 2 \\
\hline 10 & $37 / \mathrm{F}$ & 32 & 4 & 3 & 2 \\
\hline 11 & $38 / \mathrm{F}$ & 20 & $3 \cdot 5$ & $2 \cdot 5$ & $2 \cdot 5$ \\
\hline 12 & $36 / F$ & 36 & 4 & 3 & 2 \\
\hline 13 & $18 / \mathrm{F}$ & 18 & 4 & 4 & 4 \\
\hline \multicolumn{6}{|c|}{ Placebo } \\
\hline $\begin{array}{l}14 \\
15\end{array}$ & $\begin{array}{l}21 / \mathrm{M} \\
45 / \mathrm{F}\end{array}$ & $\begin{array}{l}19 \\
44\end{array}$ & $\begin{array}{l}2 \\
7 \cdot 5\end{array}$ & $\begin{array}{l}2 \\
7\end{array}$ & $\begin{array}{l}2.5 \\
7.5\end{array}$ \\
\hline $16 R$ & $22 / \mathrm{F}$ & 22 & 8 & 8 & Withdrawn after \\
\hline 17 & $51 / \mathrm{M}$ & 31 & 3 & 1.5 & 1 \\
\hline 18 & $29 / F$ & 22 & 4 & 4 & 4 \\
\hline $19 R$ & $33 / \mathrm{F}$ & 32 & 6 & 6 & $6 \cdot 5$ \\
\hline $20 \mathrm{R}$ & $23 / \mathrm{F}$ & 16 & $3 \cdot 5$ & $3 \cdot 5$ & 5 \\
\hline 21 & $36 / F$ & 36 & 4 & 4 & 2 \\
\hline 22 & $55 / F$ & 35 & 4 & $3 \cdot 5$ & $3 \cdot 5$ \\
\hline
\end{tabular}

$\mathbf{R}=$ further relapse or progression of disability.

treated patients than controls $(t=-3.46 ; \mathrm{p}<0.01)$. There were no statistical differences in duration of disease or of the progressive phase.

The results from all 50 patients in the trial are illustrated in the figure. Twenty six patients were randomised to treatment with methylprednisolone and 24 received placebo preparations. No patient given methylprednisolone was worse after treatment and no serious adverse effects were encountered during the trial. Methylprednisolone treated patients showed decreased disability scores at 4 weeks in 19 of 26 whereas $7 / 26$ subjects were unchanged. Six of seven non-responders were patients with progressive multiple sclerosis. In the control group, $7 / 24$ cases showed a decrease in disability scores at 4 weeks, 6/24 had increased disability and 10/24 were unchanged; one patient did not complete the study. These results show a significant effect in favour of methylprednisolone treatment $(t=-3.85 ; \mathrm{p}<0.001)$. The data were analysed further to determine the relative contribution of the two clinical groups.

\section{Acute relapse group}

Treatment with methylprednisolone during acute relapse resulted in a significant decrease in clinical disability scores at 1 and 4 weeks after treatment compared with controls $(t=-2.31$ and -2.57 respectively; $p<0.05$; table 2). Eight of thirteen patients had improved 1 week after starting methylprednisolone and in 4/8 cases the decrease in disability ranged from $2 \cdot 5-4 \cdot 5$ points on the Kurtzke scale.
This initial rapid response was followed by further clinical improvement in $7 / 8$ cases showing improvement by 1 week. At 4 weeks, 10/13 patients showed a decrease in disability score which was $\geqslant 1$ point on the disability scale and in four cases the decrease ranged from 3.5-5 points (table 2 ). In contrast, controls who showed a similar range of disability scores before treatment compared with methylprednisolone treated patients did not improve as a group. Two patients improved spontaneously, four were unchanged and two were worse at the end of the trial. One patient (Case 19) had a spastic paraparesis on entry to the trial which progressed and another (Case 20) who had a cervical cord lesion at entry developed an internuclear ophthalmoplegia due to a further relapse during the period of observation. One control patient (Case 16) was withdrawn from the trial 10 days after starting treatment after becoming psychotic.

\section{Progressive multiple sclerosis group}

There was a significant decrease in disability scores at 4 weeks after treatment with methylprednisolone in patients with progressive multiple sclerosis $(t=$ $-3.25 ; \mathrm{p}<0.01$; table 3 ) even though these patients were clinically more disabled before treatment than controls due to a randomisation error. Six of thirteen patients showed a reduction in disability scores which was $\geqslant 1$ point on the scale at 4 weeks and in all six cases there was improved pyramidal function, due largely to a decrease in spasticity. Two of six patients 
Table 3 Results of treatment in patients with progressive multiple sclerosis

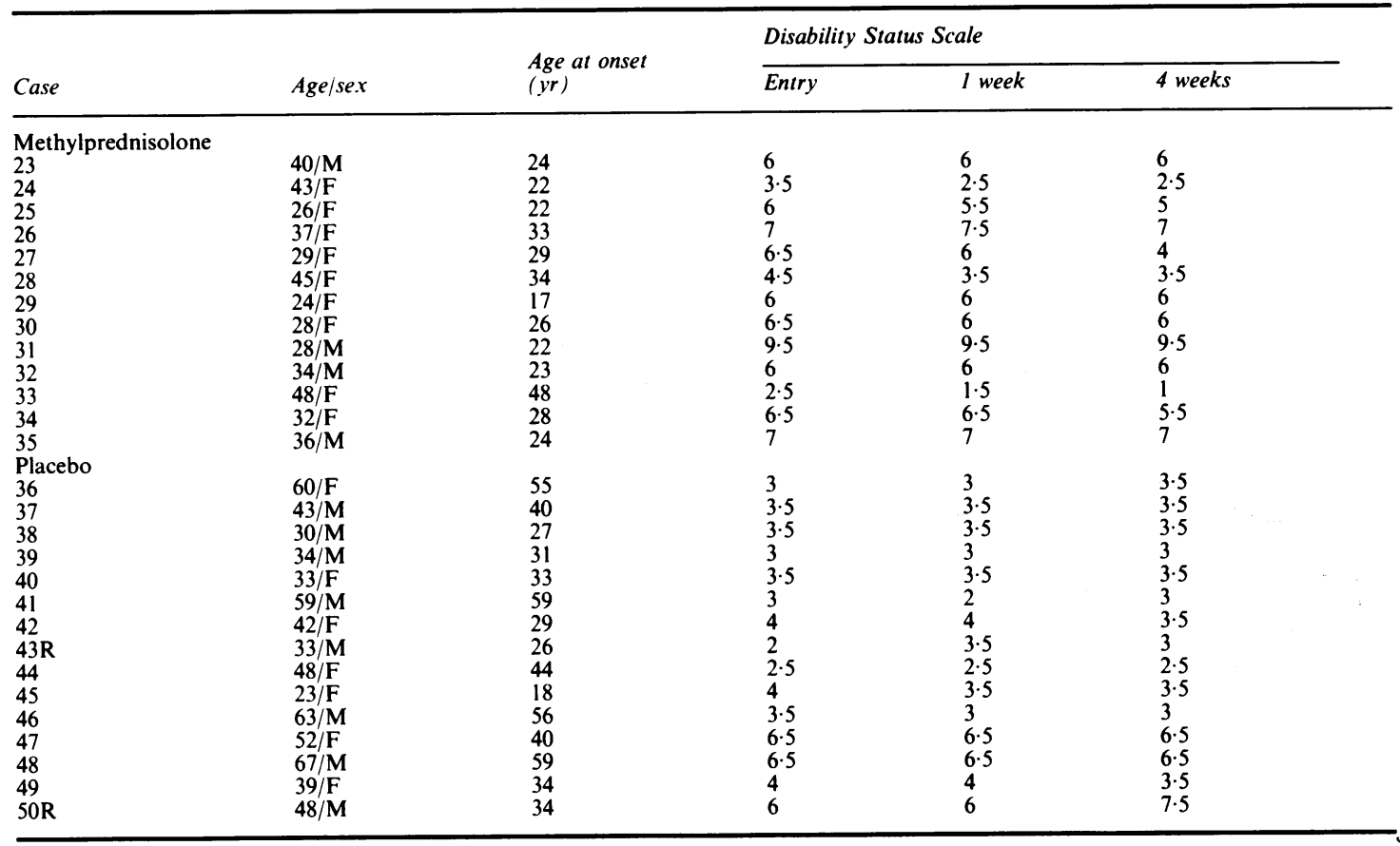

$\mathbf{R}=$ relapse.

also showed improvement in sensory function after methylprednisolone but scores in other functional systems were unchanged. There was no increase in disability in any patient treated with methylprednisolone.

Controls showed no significant change after treatment but two patients showed evidence for a relapse during the trial. Case 50 had a severe spastic paraparesis at entry and had developed diplopia due to a bilateral internuclear ophthalmoplegia when reassessed at 4 weeks; Case 43 had lost vibration sense in both lower limbs when re-examined at 1 week which was clinically asymptomatic (table 3 ).

\section{Discussion}

This study confirms previous reports that pulse therapy with high dose intravenous methylprednisolone is effective treatment for patients with multiple sclerosis in relapse $\mathrm{e}^{10-14}$ and also shows that it is beneficial in some patients with chronic progressive disease.

Clinical improvement was rapid in onset during relapse and the main decrease in disability scores occurred within one week after starting treatment although most patients were aware of subjective improvement after the third dose. This initial rapid response was followed by some further clinical improvement at 4 weeks in the majority of responsive patients. These clinical points are well illustrated by Case 1 who was unable to walk 50 metres even with aid before treatment (disability score 7) but had only? minimal disability in two functional systems one week later (disability score 2.5): Case 4 had a disability score of 6 on entry which fell to 2 at four weeks. A further five patients showed a decrease in disability of 2 points or more on the Kurtzke scale four weeks after treatment and in one patient (Case 6) this signified the presence of neurological signs only, without symptoms or disability. In contrast, controls in relapse showed no spontaneous improvement as a group: some individuals recovered but the variability of results observed after placebo treatment was consistent with the natural history of acute exacerbations of multiple sclerosis. No patient deteriorated after treatment with methylprednisolone, whereas three patients either progressed or showed clinical evidence for a further relapse during the trial after receiving placebo preparations. The rapid onset of recovery obtained with intravenous methylprednisolone, reported here and elsewhere, ${ }^{10-14}$ is particularly desirable for patients in acute relapse and achieves useful clinical improvement in the shortest possible time without the adverse effects encountered with prolonged administrations of corticosteroids by other routes. In addition, this treatment often shortens the duration of hospital admission for patients in relapse 
and will reduce demands on ancillary services thereby greatly adding to the cost-effectiveness of the treatment, despite the relative expense of the drug. In this study, all methylprednisolone treated patients were well enough to be discharged from hospital after 1 week, whereas the placebo treated cases required longer admissions, more physiotherapy and more care from attendant medical and nursing staff even when improvement occurred spontaneously.

The role of high dose pulsed intravenous methylprednisolone in patients with progressive multiple sclerosis is less certain than during relapse. Significant clinical improvement was achieved in this study even though the methylprednisolone treated group were clinically more disabled than controls at entry suggesting that this treatment may be even more effective in patients with progressive multiple sclerosis than was evident from our results. Conversely, the younger age at onset of disease in actively treated patients may have contributed to the results since this is associated with a better prognosis. ${ }^{1718}$ All six patients with decreased disability scores after methylprednisolone showed improved pyramidal function due to a decrease in spasticity, whereas cases with flaccid weakness were unchanged. Improvement in other functional systems was less marked after methylprednisolone although $2 / 6$ patients showed a modest improvement in sensation. Two placebo treated chronic progressive cases showed clinical evidence for further relapse; therefore overall five patients deteriorated clinically during the trial, all of whom received placebo treatment.

Although the effect of methylprednisolone is rapid in onset it does not prevent further relapse or progression of the disease. Long term immunological drug therapy may arrest disease progression but is slow to act and the effect may be delayed for several months. ${ }^{19}$ As there is some evidence that disease activity is continuous throughout the entire course of multiple sclerosis, even in relapsing cases, it seems logical to suggest that combined treatment with intravenous methylprednisolone followed by a long term maintenance therapy might be more effective than either agent alone. This approach has already been used with some success in the management of severe generalised myasthenia ${ }^{20}$ and other immunologically mediated diseases and permits the use of a smaller maintenance dose of immunosuppressive treatment. ${ }^{6-9}$ The possibility exists that a similar approach to treatment of multiple sclerosis would provide an additional role for methylprednisolone in the long term management of this disease.

This study has demonstrated that intravenous methylprednisolone can achieve short term improvement in patients with acute and progressive multiple sclerosis and others have shown that this regimen is more effective than ACTH. Methylprednisolone was easily administered, well tolerated and surprisingly free from serious adverse effects. Slight reddening of the face, transient ankle swelling and a metallic taste in the mouth during infusion were the most frequently reported side effects but these were mild and never as severe as with prolonged courses of intramuscular ACTH or oral corticosteroids and did not influence the blinding procedure. Furthermore, clinical use of intravenous methylprednisolone in other conditions has been associated with remarkably few serious adverse effects even with dosages considerably greater than used in this study ${ }^{21}$ although there may be more complications with repeated courses. In our experience, intravenous methylprednisolone is a safe and effective treatment for patients with multiple sclerosis and significant side effects did not occur during or immediately following the trial. It would be possible to administer this treatment on an outpatient or domiciliary basis without need for hospitalisation and this would further increase its cost-effectiveness. However, at present methylprednisolone should be reserved for patients with a severe relapse where there is a significant effect on aspects of daily living and in those patients with progressive multiple sclerosis in whom spasticity is a source of significant disability.

\section{References}

1 Miller H, Newell DJ, Ridley A. Multiple sclerosis. Treatment of acute exacerbations with corticotrophins (ACTH). Lancet 1961;2:1120-2.

2 Tourtellotte WW, Haerer AF. Use of an oral corticosteroid in the treatment of multiple sclerosis. Arch Neurol 1965;12:536-45.

3 Fog T. The long-term treatment of multiple sclerosis with corticoids. Acta Neurol Scand 1965;41(2)Suppl 13:473-83.

4 Millar JHD, Vas CJ, Norona MJ, et al. Long term treatment of multiple sclerosis with corticotrophin. Lancet 1967;ii:429-31.

5 Rose AS, Kuzma JW, Kurtzke JF, Namerow NS, Sibley WA, Tourtellotte WW. Co-operative study in the evaluation of therapy in multiple sclerosis: ACTH vs placebo: final report. Neurology 1970;20(Suppl):1-59.

6 Cole BR, Brocklebank JT, Kienstra RH, Kissane JM, Robson AM. "Pulse" methylprednisolone therapy in treatment of severe glomerulonephritis. $J$ Pediatr 1976;88:307-14.

7 Cathcart ES, Idelson BA, Scheinberg MA, Collser WG. Beneficial effects of methylprednisolone "pulse" therapy in diffuse proliferative lupus nephritis. Lancet 1976;i:163-6.

8 Ponticelli C, Zughelli P, Imbasciati E, et al. Controlled trial of methylprednisolone and chlorambucil in idiopathic membranous nephropathy. $N$ Eng $J$ Med 1984;310:946-50.

9 Imbasciati E, Gusmano R, Edefonti A, et al. Controlled 
trial of methylprednisolone pulses and low dose oral prednisone for the minimal change nephrotic syndrome. Br Med J 1985;291:1305-8.

10 Dowling PC, Bosch UV, Cook SK. Possible beneficial effect of high dose intravenous steroid therapy in acute demyelinating disease and transverse myelitis. Neurology 1980;30:33-6.

11 Buckley C, Kennard C, Swash M. Treatment of acute exacerbations of multiple sclerosis with intravenous methylprednisolone. J Neurol Neurosurg Psychiatry 1982;45:179-80.

12 Newman PK, Saunders M, Tilley PJB. Methylprednisolone therapy in multiple sclerosis. $J$ Neurol Neurosurg Psychiatry 1982;45:941-2.

13 Goas JY, Marion JL, Missoum A. High dose intravenous methylprednisolone in acute exacerbations of multiple sclerosis. J Neurol Neurosurg Psychiatry 1983;46:99.

14 Barnes MP, Bateman DE, Cleland PG, Dick DJ, Walls TJ, Newman PK, Saunders M, Tilley PJB. Intravenous methylprednisolone for multiple sclerosis in relapse. J Neurol Neurosurg Psychiatry 1985;48:157-9.

15 Compston DAS, Milligan NM, Hughes PJ, Gibbs J, McBroom V, Morgan BP, Campbell AK. A double- blind controlled trial of high dose methylprednisolone in patients with multiple sclerosis. 2: laboratory results. $J$ Neurol Neurosurg Psychiatry 1987;50:517-22.

16 McDonald WI, Halliday AM. Diagnosis and classification of multiple sclerosis. In: Multiple Sclerosis. Br Med Bull 1977;33(1):4-8.

17 Cornfavreaux C, Aimard G, Devic M. Course and prognosis of multiple sclerosis assessed by the computerised data processing of 349 patients. Brain 1980;103:281-300.

18 Thompson AJ, Hutchinson M, Brazil J, Feighery C, Martin EA. A clinical and laboratory study of benign multiple sclerosis. $Q J$ Med 1986;58:69-80.

19 Editorial. Immunological treatment in multiple sclerosis. Lancet 1980;ii:953-4.

20 Arsura E, Brunner NG, Namba T, Grob D. High-dose intravenous methylprednisolone in myasthenia gravis. Arch Neurol 1985;42:1149-53.

21 Sprung CL, Caralis PV, Marcial EH, et al. The effects of high-dose corticosteroids in patients with septic shock: a prospective controlled study. $N$ Eng $J$ Med 1984;311:1137-43. 